Rochester Institute of Technology

RIT Scholar Works

$1-1-2017$

\title{
User Experiences When Testing a Messaging App for Communication Between Individuals who are Hearing and Deaf or Hard of Hearing
}

\author{
Lisa Elliot \\ Rochester Institute of Technology \\ Michael Stinson \\ Rochester Institute of Technology \\ Syed Ahmed \\ Rochester Institute of Technology \\ Donna Easton \\ Rochester Institute of Technology
}

Follow this and additional works at: https://scholarworks.rit.edu/other

\section{Recommended Citation}

Elliot, Lisa; Stinson, Michael; Ahmed, Syed; and Easton, Donna, "User Experiences When Testing a Messaging App for Communication Between Individuals who are Hearing and Deaf or Hard of Hearing" (2017). Accessed from

https://scholarworks.rit.edu/other/932

This Conference Proceeding is brought to you for free and open access by the Faculty \& Staff Scholarship at RIT Scholar Works. It has been accepted for inclusion in Presentations and other scholarship by an authorized administrator of RIT Scholar Works. For more information, please contact ritscholarworks@rit.edu. 


\title{
User Experiences When Testing a Messaging App for Communication Between Individuals who are Hearing and Deaf or Hard of Hearing
}

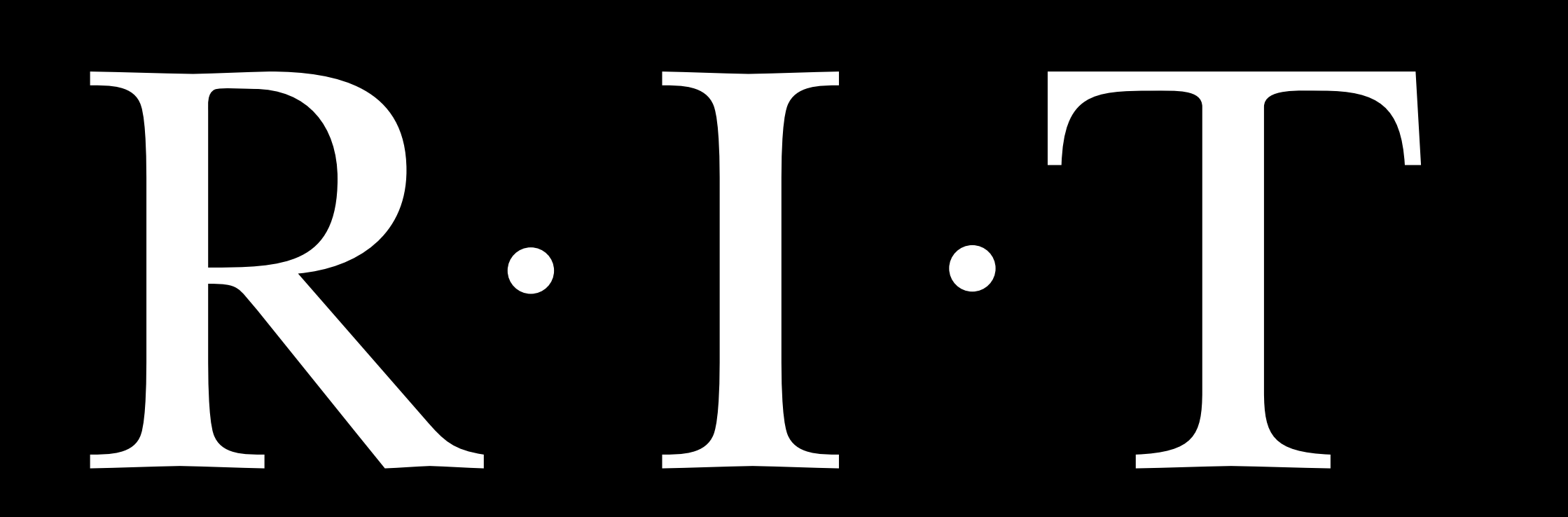

\author{
Lisa Elliot, Michael Stinson, Syed Ahmed, \& Donna Easton \\ Rochester Institute of Technology (RIT) \\ lbenrd, msserd, sxy1056, dlencr @ rit.edu
}

\section{Abstract}

This study investigated deaf and hard of hearing $(\mathrm{DHH})$ and hearing $(\mathrm{H})$

individuals' user experiences when testing a prototype messaging app with automatic speech recognition (ASR). Twelve pairs of participants, where one individual was $\mathrm{DHH}$ and the other $\mathrm{H}$ tested the app with a standardized decision-making task, displayed on either Android smartphones or tablets with full keyboards. Regardless of hearing status or type of device used, respondents were generally satisfied with the app. These findings indicate that ASR has the potential to facilitate communication between $\mathrm{DHH}$ and $\mathrm{H}$ individuals and that the technology merits further investigation.

\section{Background}

People who are $\mathrm{DHH}$ sometimes participate in small groups with individuals who are $\mathrm{H}$. DHH individuals may face barriers to full functioning in these groups due to limited access services (e.g. sign language interpreters or real-time captioning), resulting in limited contributions. ASR holds exciting promise for making spoken content accessible for $\mathrm{DHH}$ individuals in these situations. Current ASR, however, is imperfect, especially in the noisy and complex environment of multi-party meetings.

\section{Conclusions}

There were few statistically significant differences in user experiences with the prototype messaging app. Regardless of hearing status of the participants or the type of device used, participants were generally satisfied with the app. These findings indicate that ASR has potential to facilitate communication between $\mathrm{DHH}$ and hearing individuals in small groups and that the technology merits further investigation.

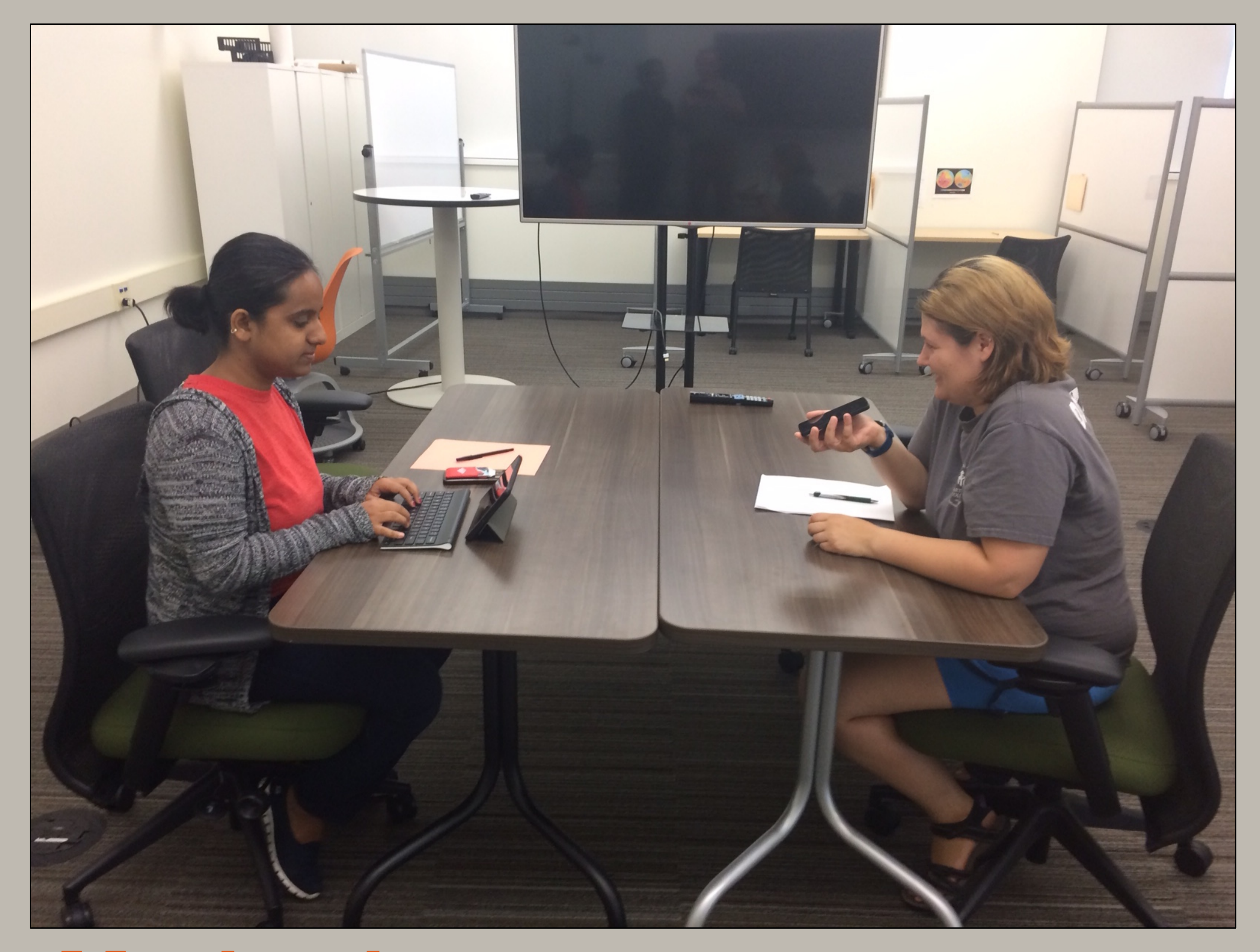

\section{Methods}

\section{Participants: Twenty-four}

postsecondary $\mathrm{DHH}(\mathrm{n}=12)$ and $\mathrm{H}(\mathrm{n}=12)$ students in 12, 2-person $(\mathrm{DHH} / \mathrm{H})$ teams. Materials: Prototype messaging app with an ASR feature that displays markup for words with less than $75 \%$ confidence; Android smartphones and tablets with full keyboards; 19-question online userexperience survey, (multiple choice, Likert-type, open-ended)-topics: collaboration, ease of use, errors, and message comprehension

Procedure: 15-minute app training; 20 minute "Lost at Sea" decision making task; user-experience survey

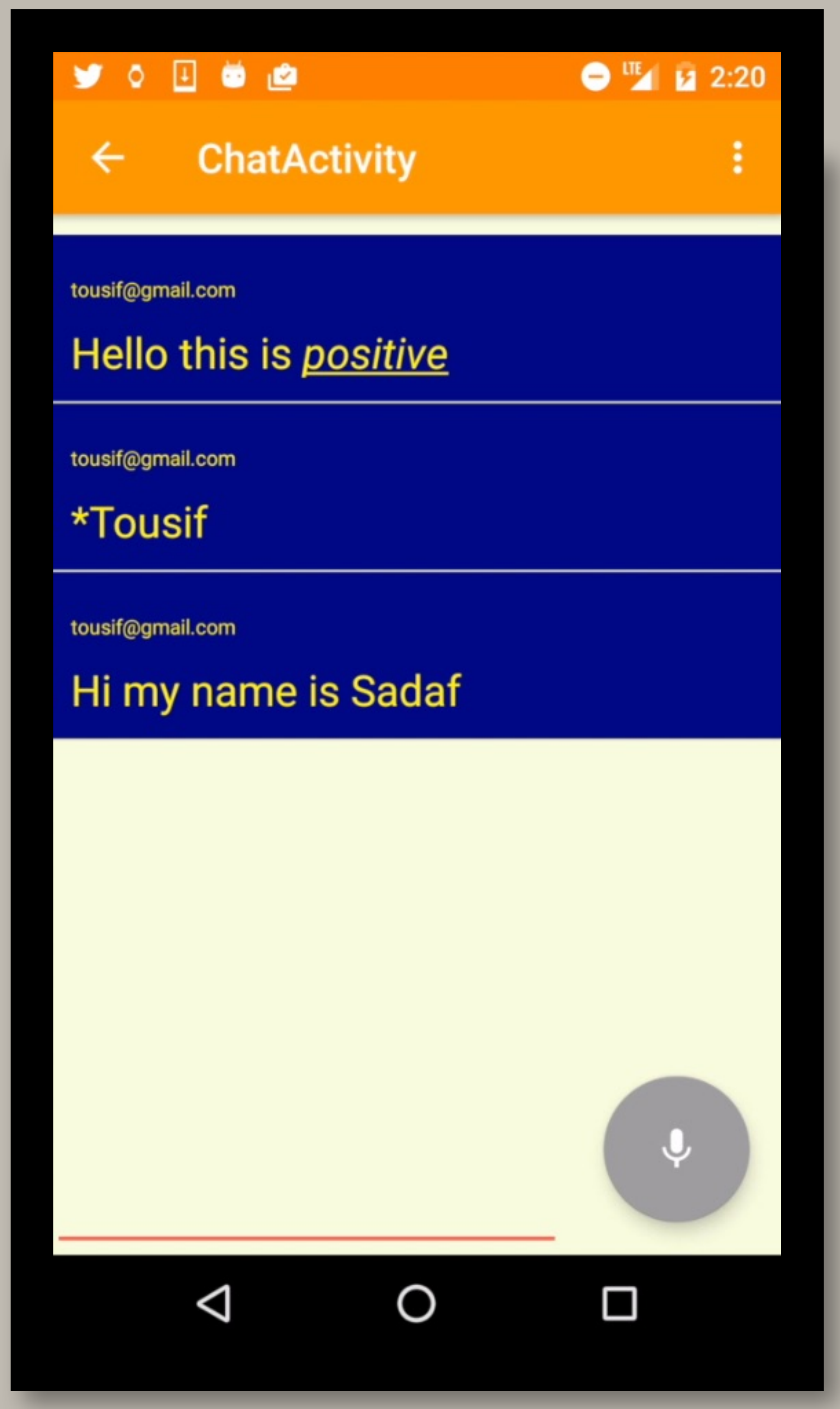

\section{Quantitative Results}

- Ease of Use-H participants found it easier to send a message with the app than the DHH did ( $p=.046, F=4.477)$.

- Comprehension-Individuals using tablets were more likely to report that their partners understood them enough to do the experiment task $(p=.000$, $F=20.087$ ).

- Collaboration-Individuals using tablets agreed more often that errors produced with ASR made it difficult to understand the information exchanged during the experiment task $(p=.043$, $F=4.632$ )

\section{Qualitative Themes and Comments}

\section{Collaboration: It allowed us to communicate thoroughly. $(\mathrm{H})$}

Comprehension: It was basically like having a normal conversation and we were both laughing a little bit. $(\mathrm{DHH})$

Ease of use: It was helpful as the app has voice recognition which makes it easier to communicate $(\mathrm{H})$

Errors: Was able to detect my voice well $(\mathrm{H})$; It underlines the errors $(\mathrm{DHH})$

Speed: Made me able to send messages much faster than typing $(\mathrm{H})$

\section{References}

[1] Foster, S. and MacLeod, J. 2003. Deaf People at Work: Assessment of Communication Among Deaf and Hearing Persons in Work Settings. International journal of audiology, 42 (2003), 128-139.

[2] Punch, R., Hyde, M., and Power, D. 2007. Career and Workplace Experiences of Australian University Graduates who are Deaf or Hard of Hearing. Journal of deaf studies and deaf education 12, 4 (2007), 504517 doi:10.1093/deafed/enm011

[3] Stinson, M., and Buckley, G. (Eds.) 2013. Taking the risk: Acquiring and living with a cochlear implant. Rochester, NY. RIT Press.

[4] Elliot, L., Stinson, M., Mallory, J., and Huenerfauth, M. 2016. Deaf and Hard of Hearing Individuals' Perceptions of Communication with Hearing Colleagues in Small Groups. In: Proceedings of the $18^{\text {th }}$ Annual International Conference on Computers and Accessibility (ASSETS16), ACM, New York, NY, USA, 271-272. http://dx.doi.org/10.1145/2982142.2982198 